\title{
Does Ricardian Equivalence Hold When Expectations are not Rational?*
}

\author{
George W. Evans \\ University of Oregon, \\ University of St Andrews \\ Seppo Honkapohja \\ Bank of Finland \\ Kaushik Mitra \\ University of St Andrews
}

August 4, 2010

\begin{abstract}
This paper considers the Ricardian Equivalence proposition when expectations are not rational and are instead formed using adaptive learning rules. We show that Ricardian Equivalence continues to hold provided suitable additional conditions on learning dynamics are satisfied. However, new cases of failure can also emerge under learning. In particular, for Ricardian Equivalence to obtain, agents' expectations must not depend on government's financial variables under deficit financing.
\end{abstract}

JEL classification: E62, D84, E21, E43

Key words: Taxation, expectations, Ramsey model, Ricardian equivalence.

${ }^{*}$ We thank the seminar audiences in the Universities of Heriot-Watt, Manchester, Oregon and St Andrews, and the May 2010 workshop on Modern Economic Forecasting, at the University of Oslo, for useful comments. Financial support from National Science Foundation Grant no. SES-1025011 is gratefully acknowledged. Any views expressed are those of the authors and do not necessarily reflect the views of the Bank of Finland. Corresponding author: Kaushik Mitra, email: Kaushik.Mitra@st-andrews.ac.uk. 


\section{Introduction}

One of the most prominent theories in macroeconomics is the Ricardian Equivalence proposition that if taxes are non-distortionary then the mix of tax and debt financing of government purchases is irrelevant in the sense that there is no impact on the equilibrium sequence of key real variables. The proposition is easily understood in the context of the "Ramsey model" in which infinitely-lived representative agents solve dynamic optimization problems and have rational expectations about the future course of the economy. The extension by Barro (1974) to an overlapping generations model with finitely-lived agents, who make bequests to their children, showed that Ricardian Equivalence holds more generally than one might think. At the same time it is widely understood that Ricardian Equivalence does not generally hold if agents are not dynamic optimizers (e.g. if agents choose current consumption on the basis of current disposable income), if households are liquidity constrained, if taxes are distortionary, or if government spending is not exogenous to financing. These and other reasons for failure of the Ricardian proposition have been examined in the voluminous theoretical and empirical literature on Ricardian Equivalence. For further discussion and references see the survey papers by Bernheim (1987), Barro (1989), Seater (1993), and Ricciuti (2003).

An apparently key assumption that has not been examined in detail is the role of rational expectations (RE). ${ }^{1}$ Although the development of microfoundations in macroeconomics went hand in hand with RE during the 1970s and most of the 1980s, the RE hypothesis has been subject to the criticism that it makes very strong assumptions about the information and knowledge agents are assumed to have. A substantial recent literature has emphasized the importance of learning dynamics arising from boundedly rational deviations from RE due to imperfect knowledge of the economy. ${ }^{2}$ For example, applications to monetary policy design include Bullard and Mitra (2002), Evans and Honkapohja (2003) and Preston (2005). This approach has also been used

\footnotetext{
${ }^{1}$ Some papers have argued that uncertainties and misperceptions about future taxes, government spending and public debt lead to failure of the Ricardian proposition. See Feldstein (1982) and Seater (1993). More recently, Eusepi and Preston (2010b) have examined related issues under learning in a New Keynesian set-up, but the validity of Ricardian Equivalence is not their central focus. For further discussion see Section 4.4.

${ }^{2}$ For the learning approach see, for example, the overviews by Evans and Honkapohja (2009), Sargent (2008), Evans and Honkapohja (2001), and Sargent (1993).
} 
in empirical analysis of macroeconomic policy, e.g. see Cogley and Sargent (2005), Bullard and Eusepi (2005), Orphanides and Williams (2005), Primiceri (2006), Sargent, Williams, and Zha (2006), Orphanides and Williams (2007), Sargent, Williams, and Zha (2009) and Eusepi and Preston (2010a).

This viewpoint raises the question, which is the focus of the current paper: if expectations are not fully rational because, for example, they are made using adaptive (or statistical) learning rules, will Ricardian Equivalence still hold? Will it at least approximately hold if expectations are approximately rational? Our answer to this question is striking: Ricardian Equivalence holds under the usual conditions but without the requirement that expectations be close to RE. If agents are dynamic optimizers, the logic behind the Ricardian Equivalence proposition goes through even when agents have non-rational forecasts, provided expectations are based on a natural information set and provided agents understand the government's budget constraint. Thus whether or not Ricardian Equivalence holds does not hinge, per se, on whether expectations are rational.

The first task of the paper is devoted to demonstrating Ricardian Equivalence, in a world without RE, and to illustrating our results. We employ the Ramsey model, a standard macroeconomic setting for demonstrating the Ricardian Equivalence proposition, ${ }^{3}$ because it allows us to study the potential impact of expectations on capital and output over time. We show that under suitable adaptive learning rules, the time paths of variables are invariant to the government financing decision, even if these paths are far from the RE paths. However, the assumptions we make are crucial, and in the remainder of the paper we show how failures of Ricardian Equivalence can arise when these assumptions are not met.

Two issues are of particular interest. When expectations are not fully rational, the issue of how the government budget is balanced out of the RE equilibrium is delicate: off the $\mathrm{RE}$ equilibrium path there will be disequilibrium budget surpluses or deficits. We show that if these off-equilibrium deficits are reconciled partly by changes in government purchases rather than lump-sum taxes, then this leads to a violation of Ricardian Equivalence. The second issue concerns the information set that agents use to make interest rate and wage forecasts. Under adaptive learning, if these forecasts are allowed to depend in part on the history of debt or taxes, then Ricardian Equivalence can fail along paths of temporary equilibria.

\footnotetext{
${ }^{3}$ For example, see Chapter 11 in the textbook by Romer (2001).
} 


\section{The Model}

We consider the standard discrete-time non-stochastic representative-agent Ramsey model with government bonds. In this context, since there are no intrinsic random shocks, RE reduces to perfect foresight. We replace perfect foresight with the assumption that expectations are formed using an adaptive learning mechanism. In the current section we take expectations as given and study the "temporary" equilibrium at a moment in time. Then in Section 3, we examine the paths of temporary equilibria with learning.

Assuming that agents are dynamic optimizers is a key assumption for our results:

Assumption 1: Households choose $c_{t}$ to maximize their intertemporal expected discounted utility, for given expectations about the future path of real interest rates, wages, and taxes.

There are a large number of identical households. At each time $t$ the household maximizes their utility subject to a flow budget constraint:

$$
\begin{gathered}
\max E_{t}^{*}\left\{\sum_{s=t}^{\infty} \beta^{s-t} \frac{c_{s}^{1-\sigma}}{1-\sigma}\right\} \text { subject to } \\
a_{s+1}=w_{s}+r_{s} a_{s}-c_{s}-\tau_{s}, \text { for all } s \geq t,
\end{gathered}
$$

for given $a_{t}$ and for given $w_{t}, r_{t}$ and $\tau_{t}$. We assume $\sigma>0$ and $0<\beta<1$. The variables $c_{s}, \tau_{s}, w_{s}$ are consumption, taxes and the real wage rate in period $s$, and $r_{s}$ is the gross real rate of return paid on both capital and government one-period bonds determined at the beginning of period $s$. By arbitrage, the government is assumed to promise the same rate of return on one-period bonds as on private capital. ${ }^{4}$ Here $a_{s} \equiv k_{s}+b_{s}$, is per capita household wealth and equals holdings of capital $k_{s}$ plus government debt $b_{s}$. The variables $w_{s}, r_{s}$ and $\tau_{s}$ are considered exogenous to the household. Labor supply is normalized to be equal to 1, and the household is subject to a No Ponzi Game condition.

Finally, $E_{t}^{*}$ denotes potentially subjective expectations at time $t$ for the future, which agents hold in the absence of perfect foresight. We assume

\footnotetext{
${ }^{4}$ An alternative approach, which would not change our results, is to assume that the common rate of return $r_{t+1}$ on capital and government debt is determined at time $t$ simultaneously with consumption $c_{t}$. In this case, consumption depends on actual $r_{t+1}$ (which depends on $k_{t+1}$, which in turn is determined in period $t$ ) and on expected future interest rates and wages.
} 
that these expectations can be represented as point expectations, i.e. the decisions of agents are assumed to be governed by the means of the subjective distribution of each variable. This "certainty equivalence" assumption, made primarily for analytical convenience, will be a good approximation if either the degree of subjective uncertainty is small (which may be more plausible in our nonstochastic setting) or the model is approximately linear (as typically assumed in macroeconomic models). The point expectations assumption has a long tradition - see, for example, Grandmont (1998) and the references therein.

The Euler equation for consumption is

$$
c_{t}^{-\sigma}=\beta E_{t}^{*}\left(r_{t+1} c_{t+1}^{-\sigma}\right) .
$$

With point expectations, from equation (2) one obtains

$$
c_{t}=\beta^{-\frac{1}{\sigma}}\left(r_{t+1}^{e}(t)\right)^{-\frac{1}{\sigma}} c_{t+1}^{e}(t),
$$

where $c_{t+1}^{e}(t)$ is short-hand notation for $E_{t}^{*} c_{t+1}$. Forward substitution of $(3)$ gives

$$
c_{t+j}^{e}(t)=c_{t} \beta^{\frac{j}{\sigma}}\left(\prod_{i=1}^{j} r_{t+i}^{e}(t)\right)^{\frac{1}{\sigma}} \equiv c_{t} \beta^{\frac{j}{\sigma}}\left(D_{t, t+j}^{e}(t)\right)^{\frac{1}{\sigma}} .
$$

Here $r_{t+i}^{e}(t)$ refers to expectations of the interest rate $r_{t+i}$ formed at time $t$, i.e., $E_{t}^{*} r_{t+i}$, and $D_{t, t+j}^{e}(t)$ denotes the expectations of the interest rate factor $D_{t, t+j}$ formed at time $t$, defined as

$$
D_{t, t+j}^{e}(t)=\prod_{i=1}^{j} r_{t+i}^{e}(t), j \geq 1 .
$$

Let $\tau_{t+j}^{e}(t)$ and $a_{t+j}^{e}(t)$ denote the expected lump-sum tax and net assets in period $t+j$ forecasted at time $t$. The household plans must also satisfy the transversality condition

$$
\lim _{T \rightarrow \infty}\left(D_{t, t+T-1}^{e}(t)\right)^{-1} a_{t+T}^{e}(t)=0 .
$$

Using forward substitution in the flow household budget constraint and equation (6) yields the intertemporal budget constraint of the consumer,

$$
0=r_{t} a_{t}+\sum_{j=1}^{\infty}\left(D_{t, t+j}^{e}(t)\right)^{-1}\left(w_{t+j}^{e}(t)-c_{t+j}^{e}(t)-\tau_{t+j}^{e}(t)\right)+w_{t}-c_{t}-\tau_{t}
$$


for given expectations $\left\{r_{t+j}^{e}(t)\right\},\left\{w_{t+j}^{e}(t)\right\},\left\{\tau_{t+j}^{e}(t)\right\}$. Substituting in the iterated Euler equation (4), one gets the consumption function

$$
c_{t}\left(1+S_{D}^{e}(t)\right)=r_{t} a_{t}+w_{t}-\tau_{t}+\sum_{j=1}^{\infty}\left(D_{t, t+j}^{e}(t)\right)^{-1}\left(w_{t+j}^{e}(t)-\tau_{t+j}^{e}(t)\right),
$$

where

$$
S_{D}^{e}(t) \equiv \sum_{j=1}^{\infty} \beta^{j / \sigma}\left(D_{t, t+j}^{e}(t)\right)^{\sigma^{-1}-1}
$$

which shows that consumption depends on expectations of future interest rates and wages. The role of the path of the expected interest rates and wages, in the absence of perfect foresight, in determining consumption in the Ramsey model has been recognized for some time. See for example, Blanchard and Fischer (1989), pp. 51-52. As emphasized in the learning literature, perfect foresight is implausible except as an outcome of a learning process.

We can rewrite the consumption function as

$$
c_{t}\left(1+S_{D}^{e}(t)\right)=r_{t} a_{t}+P V_{t}^{e}(w)-P V_{t}^{e}(\tau),
$$

where the present value expressions

$$
\begin{aligned}
& P V_{t}^{e}(w)=w_{t}+\sum_{j=1}^{\infty}\left(D_{t, t+j}^{e}(t)\right)^{-1} w_{t+j}^{e}(t) \text { and } \\
& P V_{t}^{e}(\tau)=\tau_{t}+\sum_{j=1}^{\infty}\left(D_{t, t+j}^{e}(t)\right)^{-1} \tau_{t+j}^{e}(t)
\end{aligned}
$$

are assumed to be finite. ${ }^{5}$

The consumption function (8), obtained from Assumption 1 using the point expectations assumption, follows the "infinite-horizon" approach of the learning literature adopted, for example, by Preston (2005). In the learning literature an alternative approach often followed is based on "Euler-equation" learning, see e.g. Evans and Honkapohja (2001), Ch. 10, Bullard and Mitra (2002) and Evans and Honkapohja (2003). On the latter approach agents forecast one period in advance and use (3) as a decision rule. In the current

\footnotetext{
${ }^{5}$ Throughout the paper, we assume all relevant expected present value sums are finite.
} 
paper we follow the infinite-horizon approach precisely because the shorthorizon Euler-equation approach does not allow agents to anticipate explicitly the implications of future fiscal actions; see Evans, Honkapohja, and Mitra (2009) for a fuller discussion.

We now turn to the production side of the Ramsey model, which is standard. The production function in intensive form is given by $y_{t}=f\left(k_{t}\right)$, where $Y_{t}$ is output, $K_{t}$ is capital, $L_{t}$ is labour, $k_{t}=K_{t} / L_{t}, y_{t}=Y_{t} / L_{t}$, and $f(k) \equiv F(k, 1) ; F(K, L)$ being the underlying production function with constant returns to scale. The Cobb-Douglas form $f(k)=k^{\alpha}$ is assumed below in the examples. For simplicity, there is neither population nor productivity growth. $0 \leq \delta \leq 1$ denotes the proportional rate of depreciation of the capital stock. Profit maximization by firms entails that the real wage rate $w_{t}$ and the gross interest rate $r_{t}$ satisfy ${ }^{6}$

$$
\begin{aligned}
w_{t} & =f\left(k_{t}\right)-k_{t} f^{\prime}\left(k_{t}\right), \\
r_{t} & =1-\delta+f^{\prime}\left(k_{t}\right) .
\end{aligned}
$$

The government's flow budget constraint is

$$
b_{t+1}+\tau_{t}=g_{t}+r_{t} b_{t},
$$

where $g_{t}$ is government purchases of the good. Market clearing determines $k_{t+1}$ from

$$
k_{t+1}=f\left(k_{t}\right)-c_{t}-g_{t}+(1-\delta) k_{t} .
$$

Given pre-determined variables $k_{t}, b_{t}$, current fiscal policy variables $g_{t}, \tau_{t}$, and expectations $\left\{r_{t+j}^{e}(t)\right\}_{j=1}^{\infty},\left\{w_{t+j}^{e}(t)\right\}_{j=1}^{\infty},\left\{\tau_{t+j}^{e}(t)\right\}_{j=1}^{\infty}$, a temporary equilibrium at time $t$ is defined by the consumption function (8), the wage rate (9), the interest rate (10), the government budget constraint (11), and market clearing (12).

Next, we show that the consumption function can be written in terms of the present value of labor income $P V_{t}^{e}(w)$ and of government spending

$$
P V_{t}^{e}(g)=g_{t}+\sum_{j=1}^{\infty}\left(D_{t, t+j}^{e}(t)\right)^{-1} g_{t+j}^{e}(t) \text {. }
$$

\footnotetext{
${ }^{6}$ Note that firms face a static problem, so that there is no need for them to forecast future interest or wage rates.
} 
For this result we need two assumptions concerning household perceptions of the government budget constraint. First, we assume that households understand the flow budget constraint of the government (11). Second, households believe that that government debt does not explode too fast, so that its (expected) limiting present value is zero. Thus we assume:

Assumption 2: Households' forecasts (i) are consistent with the flow budget constraint (11) and (ii) satisfy

$$
\lim _{j \rightarrow \infty}\left(D_{t, t+j}^{e}(t)\right)^{-1} b_{t+j+1}^{e}(t)=0 .
$$

Note that the flow budget constraint of the government is an accounting relationship, whereas the intertemporal budget constraint in Assumption 2 is a subjective belief of the households about the government.

We now establish the result about the consumption function, which was mentioned above:

Lemma 1 Under Assumptions 1 and 2, the consumption function (8) can be written as

$$
c_{t}\left(1+S_{D}^{e}(t)\right)=r_{t} k_{t}+P V_{t}^{e}(w)-P V_{t}^{e}(g) .
$$

Proof. Since $a_{t} \equiv k_{t}+b_{t}$, to establish the result it is sufficient to show that

$$
r_{t} b_{t}+P V_{t}^{e}(g)=P V_{t}^{e}(\tau) .
$$

Substituting recursively (11) forward,

$$
0=r_{t} b_{t}+\left(g_{t}-\tau_{t}\right)+\sum_{j=1}^{J-1} D_{t, t+j}^{-1}(t)\left(g_{t+j}-\tau_{t+j}\right)-D_{t, t+J-1}^{-1}(t) b_{t+J} .
$$

Using Assumption 2(i) we have

$0=r_{t} b_{t}+\left(g_{t}-\tau_{t}\right)+\sum_{j=1}^{J-1}\left(D_{t, t+j}^{e}(t)\right)^{-1}\left(g_{t+j}^{e}(t)-\tau_{t+j}^{e}(t)\right)-\left(D_{t, t+J-1}^{e}(t)\right)^{-1} b_{t+J}^{e}(t)$

and using Assumption 2(ii) it follows that

$$
0=r_{t} b_{t}+\left(g_{t}-\tau_{t}\right)+\sum_{j=1}^{\infty}\left(D_{t, t+j}^{e}(t)\right)^{-1}\left(g_{t+j}^{e}(t)-\tau_{t+j}^{e}(t)\right),
$$


which is (14).

It follows from Lemma 1 that the temporary equilibrium of the economy can equivalently be defined in terms of the model equations, the predetermined variables, and the expectations of interest rates, wages and government spending $\left\{g_{t+j}^{e}(t)\right\}_{j=1}^{\infty}$, rather than taxes $\left\{\tau_{t+j}^{e}(t)\right\}_{j=1}^{\infty}$. An implication of the Lemma is that with some additional assumptions, Ricardian Equivalence holds in the temporary equilibrium.

Proposition 2 Assume that neither $g_{t}$ nor $\left\{r_{t+j}^{e}(t), w_{t+j}^{e}(t), g_{t+j}^{e}(t)\right\}_{j=1}^{\infty} d e-$ pend on current government financing variables $\tau_{t}$ and $b_{t+1}$. Then Ricardian Equivalence holds in the temporary equilibrium at time $t$, i.e. $c_{t}$ is independent of $\tau_{t}$ and $b_{t+1}$.

According to Proposition 2, given pre-determined variables and expectations about the future, we have Ricardian Equivalence in the temporary equilibrium. A crucial assumption is that expectations do not react within the period to taxes. If, for example, an increase in taxes $\tau_{t}$ leads agents to revise upward their expectations of future government spending, then we no longer have Ricardian Equivalence even in the temporary equilibrium at time $t^{7}$

Next, we distinguish Ricardian Equivalence in the temporary equilibrium at a single moment of time from the stronger notion of Ricardian Equivalence for the entire path of temporary equilibria with learning. The latter also depends on the way in which expectations are revised over time, as we now discuss.

\section{Ricardian Equivalence for Paths of Tempo- rary Equilibria with Learning}

In considering the evolution of the economy over time we use the temporary equilibrium approach that is standard in the adaptive learning literature, and which has antecedents in Hicks (1946), Parts III and IV, and Grandmont (1982). For a discussion see Radner (1982). In the context of infinite-horizon agents solving dynamic optimization problems, our approach can be viewed

\footnotetext{
${ }^{7}$ It appears to be this type of concern that is discussed, for instance, on p. 3 in Feldstein (1982).
} 
as a version of the "anticipated utility" approach formulated by Kreps (1998) and discussed in Sargent (1999), and Cogley and Sargent (2008).

At each time $t$ agents solve their dynamic optimization problem, given forecasts of the future based on an estimated forecasting model, and use the solution to make their time $t$ decisions. At time $t+1$ agents update their forecasting model and their forecasts of future variables, and re-solve their dynamic optimization problem in order to make their time $t+1$ decisions. In the anticipated utility approach recommended by Kreps, agents update their forecasts over time but do not take into account the fact that their forecasting model will be revised in future periods. Clearly this is a bounded rationality approach, since a full Bayesian approach would recognize the uncertainty in the parameters of the estimated forecasting model. However, as noted by Cogley and Sargent (2008), a full Bayesian approach in macroeconomic settings is typically "too complicated to be implemented," and thus the anticipated utility approach is an appealing implementation of bounded rationality. ${ }^{8}$

Consider, therefore, the path of temporary equilibria in a Ramsey economy that starts with some initial capital stock $k_{0}$, public debt $b_{0}$ and beliefs about the future path of the economy. When agents are learning, the economy evolves along a path of temporary equilibria $\left\{c_{t}, k_{t+1}, r_{t+1}, w_{t+1}\right.$, $\left.b_{t+1}\right\}_{t=0}^{\infty}$ for given fiscal policy rules that determine $\left\{\left(g_{t}, \tau_{t}\right)\right\}_{t=0}^{\infty}$ and debt dynamics satisfying our assumptions. ${ }^{9}$ In the preceding section it was shown that under Assumptions 1 and 2, the consumption function (13) depends on expectations $\left\{r_{t+j}^{e}(t), w_{t+j}^{e}(t), g_{t+j}^{e}(t)\right\}_{j=1}^{\infty}$. In some of the examples below, $g_{t}$ is an exogenous sequence, while in others it is determined by a fiscal rule. In the latter case, we assume that consumers use the rule to forecast future government spending, in line with Assumption 2.

Ricardian Equivalence under RE requires that government spending does not depend on taxes or debt, and this assumption is also needed for Ricardian Equivalence along learning paths. We therefore assume:

Assumption 3: Government spending $g_{t}$ either is exogenous or is a predetermined variable that depends only on $\left\{k_{s}, r_{s}, w_{s}, g_{s-1}\right\}_{s=0}^{t}$.

\footnotetext{
${ }^{8}$ Furthermore, Cogley and Sargent (2008) show that the anticipated utility approach often provides an excellent approximation to Bayesian decisions.

${ }^{9}$ We make additional assumptions below on the policy rule determining $g_{t}$.
} 
Next, we formulate the assumptions about expectations formation and learning, which leads to the main result: the conditions under which Ricardian Equivalence holds for whole sequence of temporary equilibria, $t=$ $0,1,2, \ldots$. We first define the concept of a learning mechanism and make an assumption about the associated information set.

Definition: An adaptive learning mechanism is a mapping from the time $t$ information set $I_{t}$ to the sequence of expectations $\left\{r_{t+j}^{e}(t), w_{t+j}^{e}(t), g_{t+j}^{e}(t)\right\}_{j=1}^{\infty}$, for $t \geq 0$, together with an initial set of expectations $\left\{r_{j}^{e}(-1), w_{j}^{e}(-1), g_{j}^{e}(-1)\right\}_{j=0}^{\infty}$.

Assumption 4: The information set at $t \geq 0$ for the adaptive learning mechanism consists of

$$
I_{t}=\left\{k_{s}, r_{s}, w_{s}, g_{s}\right\}_{s=0}^{t} \cup\left\{\left\{r_{s+j}^{e}(s), w_{s+j}^{e}(s), g_{s+j}^{e}(s)\right\}_{j=1}^{\infty}\right\}_{s=-1}^{t-1} .
$$

It would be possible to allow $I_{t}$ to include a dependence on lagged consumption, but it is crucial that $I_{t}$ does not include current or past values of taxes or debt.

Our formulation in terms of an adaptive learning mechanism for how expectations are updated over time is very general and includes various standard statistical forecasting rules as special cases. Examples include forecasts based on sample means, exponentially-weighted moving averages ("adaptive expectations") or models using parameters estimated by least-squares or similar methods. We keep the formulation general in order to isolate the specific assumptions required for our results.

Given $k_{0}$ (and hence $\left.r_{0}, w_{0}\right), b_{0}, g_{-1}$ and initial expectations $\left\{r_{j}^{e}(-1)\right.$, $\left.w_{j}^{e}(-1), g_{j}^{e}(-1)\right\}_{j=0}^{\infty}$, a path of (temporary) equilibria with learning is a sequence $\left\{c_{t}, g_{t+1}, k_{t+1}, r_{t+1}, w_{t+1}, b_{t+1}\right\}_{t=0}^{\infty}$ in which expectations $\left\{r_{t+j}^{e}(t)\right.$, $\left.w_{t+j}^{e}(t), g_{t+j}^{e}(t)\right\}_{j=1}^{\infty}$ at each time $t$ satisfy an adaptive learning mechanism and in which the temporary equilibrium equations (9)-(13) and the government fiscal policy rules are satisfied.

Definition: The model exhibits Ricardian Equivalence if, for all initial conditions, the sequence of variables $\left\{c_{t}, k_{t+1}, r_{t+1}, w_{t+1}\right\}_{t=0}^{\infty}$ along the path of equilibria with learning is independent of the government financing policy.

The key result of the paper is:

Theorem 3 The Ramsey model exhibits Ricardian Equivalence under Assumptions 1 through 4. 
Proof. The result is shown using induction on $t$. By Assumptions 3 and 4 , $g_{0}$ and $\left\{r_{j}^{e}(0), w_{j}^{e}(0), g_{j}^{e}(0)\right\}_{j=1}^{\infty}$ are independent of the government financing policy. It then follows from Proposition 2 that the consumption function satisfies Ricardian Equivalence. Thus $c_{0}$ and $\left(k_{1}, r_{1}, w_{1}\right)$ are independent of the financing policy of the government. Suppose now for some $t \geq 1$ that $\left(c_{s-1}, k_{s}, r_{s}, w_{s}\right)$ and $\left\{r_{s-1+j}^{e}(s-1), w_{s-1+j}^{e}(s-1), g_{s-1+j}^{e}(s-1)\right\}_{j=1}^{\infty}$, for $s=1, \ldots, t$, are independent of the government financing policy. Then by Assumptions 3 and 4, and Proposition 2, $\left\{r_{t+j}^{e}(t), w_{t+j}^{e}(t), g_{t+j}^{e}(t)\right\}_{j=1}^{\infty}, c_{t}, g_{t}$ and hence $\left(k_{t+1}, r_{t+1}, w_{t+1}\right)$ are independent of the financing policy. It follows by induction that $\left\{c_{t}, k_{t+1}, r_{t+1}, w_{t+1}\right\}_{t=0}^{\infty}$ is independent of the financing policy.

The theorem makes it very clear that rational expectations is not required for validity of the Ricardian proposition. If one makes assumptions on the economy guaranteeing Ricardian Equivalence under RE, then the equivalence also holds under learning given Assumptions 1-4. The essential ingredients are that agents are dynamic optimizers and they understand the structure of the government flow budget constraints and believe that the intertemporal budget constraint will hold. The other essential ingredient is that agents' expectations do not depend on government financing variables.

\section{$4 \quad$ Examples}

We now develop several examples that highlight the role of different assumptions behind the results. In each example we assume that the government spending and tax policies are known. Assumptions 1 and 2 are assumed satisfied throughout, so that the consumption function is given by equation (13) of Lemma $1 .^{10}$ Assumption 3 is satisfied if government spending is exogenous. ${ }^{11}$ Example 1 illustrates Ricardian Equivalence under learning in this case.

\footnotetext{
${ }^{10}$ Actually, in our examples Assumptions 1 and 2(i) are sufficient to imply (13), since for these examples iteration of the flow government budget constraint over a finite horizon is sufficient to establish (14).

${ }^{11}$ Bohn (1992) has shown that under RE Ricardian equivalence fails if government spending is determined as optimal welfare maximizing policy (or in a public choice setting).
} 


\subsection{Example with exogenous government spending}

Example 1: (exogenous government spending). Suppose government spending is exogenous and constant at the level $\bar{g}$. The initial level of government debt is assumed to be $b_{0}=0$. Under balanced budget financing $\tau_{t}=g_{t}=\bar{g}$ for all $t$, and $b_{t}=0$ each period. We consider an alternative financing policy in which taxes are held below $\bar{g}$ for $T$ periods, after which debt is stabilized.

$$
\begin{aligned}
g_{t} & =\bar{g}, \\
\tau_{t} & =\left\{\begin{array}{c}
\bar{\tau}<\bar{g} \text { for } 0 \leq t<T \\
\bar{g}+\left(r_{t}-1\right) b_{T} \text { for } t \geq T
\end{array} .\right.
\end{aligned}
$$

Note that after period $T$ taxes are raised to levels that covers permanent government spending plus (net) interest payment on public debt. It is easily verified that $b_{t}>0$ for $t \geq 1$, and that $b_{t}=b_{T}$ for all $t>T$. Thus as long as $r_{t+j}^{e}(t)$ are bounded above one, we have $\lim _{j \rightarrow \infty}\left(D_{t, t+j}^{e}(t)\right)^{-1} b_{t+j+1}^{e}(t)=0$ and also $P V_{t}(g)$ and $P V_{t}(\tau)$ are finite.

For the adaptive learning mechanism it is assumed that in forecasting wages and interest rates agents use the simple adaptive expectations rules

$$
\begin{aligned}
r_{t+i}^{e}(t) & =r^{e}(t) \text { where } r^{e}(t)=r^{e}(t-1)+\gamma\left(r_{t}-r^{e}(t-1)\right) \text { and } \\
w_{t+i}^{e}(t) & =w^{e}(t) \text { where } w^{e}(t)=w^{e}(t-1)+\gamma\left(w_{t}-w^{e}(t-1)\right),
\end{aligned}
$$

for all $i=1,2, \ldots$ and for all $t=0,1,2, \ldots$. In the learning literature these are also called steady-state adaptive learning rules with constant gain, where $0<\gamma \leq 1$ is the "gain" parameter that controls how much expectations adjust to forecast errors. ${ }^{12}$ With these adaptive learning mechanisms agents estimate and forecast the future values of the interest rate and wages under the assumption that the perceived time profile is flat. ${ }^{13}$

We remark that more generally agents' forecasts of future values of $r_{t}$ and $w_{t}$ might depend on the capital stock in view of equations (9) and (10). In stochastic settings this dependence can be estimated using least-squares

\footnotetext{
${ }^{12}$ Constant-gain learning means that past data is discounted exponentially. Traditional least-squares learning corresponds to decreasing gain $\gamma_{t}=1 / t$ and in this case all data receive an equal weight. The results for decreasing gain would be similar, provided agents have been learning for a long period, so that the gain is "small" when the policy change is announced.

${ }^{13}$ Adaptive learning rules that yield a time-varying profile for expected future interest rates are straightforward to develop, e.g. see Evans, Honkapohja, and Mitra (2009), Section 4.
} 
adaptive learning rules. However, as the current setting is nonstochastic, it is not advisable for agents to estimate both intercept and slope parameters in regression relations because of emerging perfect multicollinearity as the economy converges to the steady state. ${ }^{14}$ In our examples below, the adaptive learning rules (16)-(17) converge over time to perfect foresight.

If the economy begins in a steady state at $t=0$, i.e. $k_{0}=\bar{k}, r_{0}=\bar{r} \equiv$ $1-\delta+f^{\prime}(\bar{k})$, and $w_{0}=\bar{w} \equiv f(\bar{k})-\bar{k} f^{\prime}(\bar{k})$ (see the Appendix for the steady state values and computation of RE dynamics), then under RE, $k_{t}=\bar{k}$ for all $t=1,2,3, \ldots$, and of course under $\mathrm{RE}$ this holds regardless of whether the budget is balanced in every period, or deficit financing is used.

More generally, initial conditions for the economy are given by $k_{0}$ and $b_{0}$ and, in the case of learning, initial expectations $r^{e}(-1)$ and $w^{e}(-1)$. Unless all initial conditions correspond to the steady state, the path of temporary equilibria with learning will differ from the RE path. Nevertheless, by Theorem 3 of the previous section, Ricardian Equivalence holds under learning even when the divergence from the $\mathrm{RE}$ path is potentially large.

We illustrate this point numerically. ${ }^{15}$ The parameter values chosen are $\sigma=1, \beta=0.99, \delta=0.03, \alpha=1 / 3, \bar{g}=0.4, \bar{\tau}=0.3, T=20$, and $\gamma=1 / 20$ in the learning rule.

Figure 1 plots the dynamics of consumption and capital under learning and $\mathrm{RE}$ when the initial capital stock $k_{0}$ is perturbed by $5 \%$ from its steady state value, i.e., we set $k_{0}=1.05 \bar{k}$ with the corresponding initial market clearing interest rates and wage rates $r_{0}=1-\delta+f^{\prime}\left(k_{0}\right)$ and $w_{0}=f\left(k_{0}\right)-k_{0} f^{\prime}\left(k_{0}\right)$ accordingly perturbed via the equations (10) and (9). Under learning, the initial interest rate and wage rate expectations are set equal to these latter values, i.e., $r^{e}(-1)=r_{0}$ and $w^{e}(-1)=w_{0}$, which under our learning rule implies also that $r^{e}(0)=r_{0}$ and $w^{e}(0)=w_{0}$. The solid line in the figures depict the paths of equilibria with learning (under both balanced budget and deficit financing since there is Ricardian Equivalence under learning), while the dashed line denotes the RE paths.

As is obvious from the figure, the differences between the learning path and the RE path are substantial. The dynamics under RE follow the standard saddle-path solution, i.e., starting from above, capital and consumption decline monotonically to their steady-state values. Under learning, because

\footnotetext{
${ }^{14}$ See Evans and Honkapohja (1998) and Evans and Honkapohja (2001), pp. 152-154, for a discussion of the subtle differences of learning in deterministic and stochastic settings.

${ }^{15}$ The Appendix provides further details for computing the learning path. The Mathematica routines for the numerical results are available on request.
} 
the expected interest-rate profile initially lies below the RE path, consumption is higher under learning and the capital-stock declines more quickly than under RE. This leads to cyclical over-shooting under learning, with eventual convergence to the steady state as expectational errors are corrected. The convergent cyclical dynamics under learning appears robust to changes in parameter values.
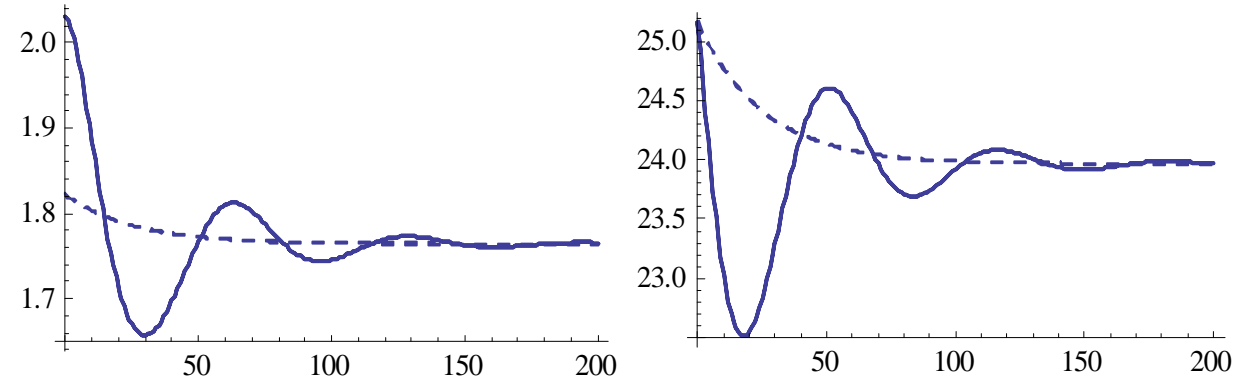

Figure 1: Paths of consumption (left-hand figure) and capital (right-hand figure) under learning (solid line) and RE (dashed line) when initial capital is above the steady state in Example 1.

Figure 2 plots the dynamics of debt under learning and under RE for the case where there is deficit financing and initial public debt is set at zero. There are differences in debt dynamics under learning and RE that are driven by the differences in the interest rates along the two paths. In the numerical illustration the two debt levels are plotted from period 15 to 25. We have omitted the initial periods in which debt under learning is also higher but the differences are very small since the initial debt is assumed to be zero. These differences would be magnified if the initial debt level were substantially above zero.

In this numerical example, the capital stock under learning initially falls below the RE path for a substantial length of time, which implies that the interest rate under $\mathrm{RE}$ is lower than under learning during these periods. This leads to a higher path and permanent level of public debt under learning than under RE. However, despite the differences in the paths of the economy under learning and RE there is Ricardian Equivalence in both cases, i.e. the consumption and capital paths under deficit finance are identical to the corresponding paths with balanced budgets. 


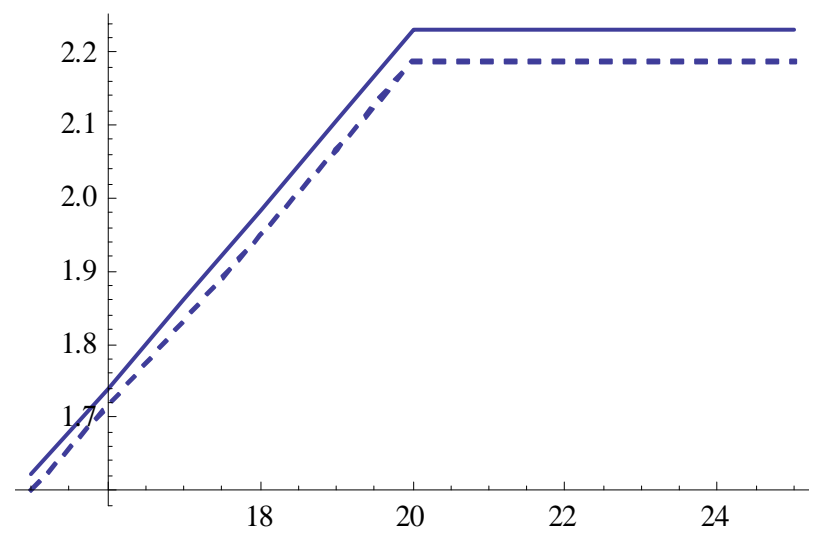

Figure 2: Paths of debt under RE (dashed line) and under learning (solid line) under deficit financing in Example 1.

\subsection{Examples with endogenous government spending}

It is known that if government spending is endogenous then Ricardian Equivalence can fail under rational expectations and therefore also under learning. As a simple example, we briefly consider the following.

Example 2: (endogenous government spending). Assume $b_{0}=0$. Under balanced budget financing $g_{t}=\tau_{t}=\bar{g}$ for all $t$, while under deficit financing

$$
\begin{gathered}
g_{t}=\left\{\begin{array}{c}
\bar{g} \text { for } 0 \leq t<T \\
\bar{g}-\left(r_{t}-1\right) b_{T} \text { for } t \geq T
\end{array}\right. \\
\tau_{t}=\left\{\begin{array}{c}
\bar{\tau}<\bar{g} \text { for } 0 \leq t<T \\
\bar{g} \text { for } t \geq T
\end{array}\right.
\end{gathered}
$$

Thus, after period $T$ government spending is reduced by an amount equal to (net) interest payment on public debt. Again it is easily verified that $b_{t}>0$ for $t \geq 1$, and that $b_{t}=b_{T}$ for all $t>T$.

This fiscal rule violates our Assumption 3 and it can easily be verified that we do not have Ricardian Equivalence either under RE or learning. The failure arises from the endogeneity of government spending which here is the result of a mechanical rule in contrast to the model of Bohn (1992), which focuses on consequences of optimizing government behavior.

However, it is also possible to construct variations of this example in which Ricardian Equivalence holds under RE but not under learning. Consider the 
following fiscal rule in which the failure of Ricardian Equivalence arises if expectations deviate from RE and government spending is used to partly reconcile the out-of-equilibrium budget deficits. For simplicity, it is now assumed that the economy is initially in the steady state, i.e. $k_{0}=\bar{k}$. We continue to assume $b_{0}=0$.

Example 3: (potentially endogenous government spending). Under balanced budget financing $g_{t}=\tau_{t}=\bar{g}$ and $b_{t}=0$. We now assume that under deficit financing

$$
\begin{aligned}
g_{t} & =\left\{\begin{array}{c}
\bar{g} \text { for } 0 \leq t<T \\
\bar{g}+\left(\beta^{-1}-r_{t}\right) b_{T} \text { for } t \geq T
\end{array}\right. \\
\tau_{t} & =\left\{\begin{array}{c}
\bar{\tau}<\bar{g} \text { for } 0 \leq t<T \\
\bar{g}+\left(\beta^{-1}-1\right) b_{T} \text { for } t \geq T
\end{array}\right.
\end{aligned}
$$

Under deficit financing, debt is again stabilized at the level $b_{T}$ for $t>T$.

Example 3 differs from Example 1 in that after period $T$ taxes are at a level that pays for the permanent level of government spending and the steady-state interest on public debt while under learning any deviation between the steady-state and actual interest rates on debt is paid for by a corresponding adjustment in the level of government spending. Thus, government spending is potentially endogenous in Example $3 .^{16}$

In Figure 3, paths of temporary equilibria with learning in regimes of deficit- and balanced-budget financing are illustrated numerically for the fiscal regime of Example 3. We again use the learning rules (16)-(17). Wage expectations are assumed to be initially at their steady state value $w^{e}(-1)=w^{e}(0)=\bar{w}$, while interest rate expectations are initially above the steady state value by one percentage point, i.e. $r^{e}(-1)$ is set so that $r^{e}(0)=1.01 r_{0}$. We set the following numerical parameter values for these figures: $\sigma=1, \beta=0.95, \delta=0.1, \alpha=1 / 3, \bar{g}=0.4, \bar{\tau}=0.3, T=20$, and $\gamma=1 / 40$ in the learning rule. As $\bar{\tau}<\bar{g}$, we have debt financing shown by the thick solid curves. The learning paths of consumption and capital under balanced budget $(\bar{\tau}=\bar{g})$ are shown by the thin solid curves. For reference, the RE path, which is a steady state in this numerical case, is shown as the dashed line.

\footnotetext{
${ }^{16}$ This endogeneity is the source of the deviation from Ricardian Equivalence found in Evans, Honkapohja, and Mitra (2009).
} 

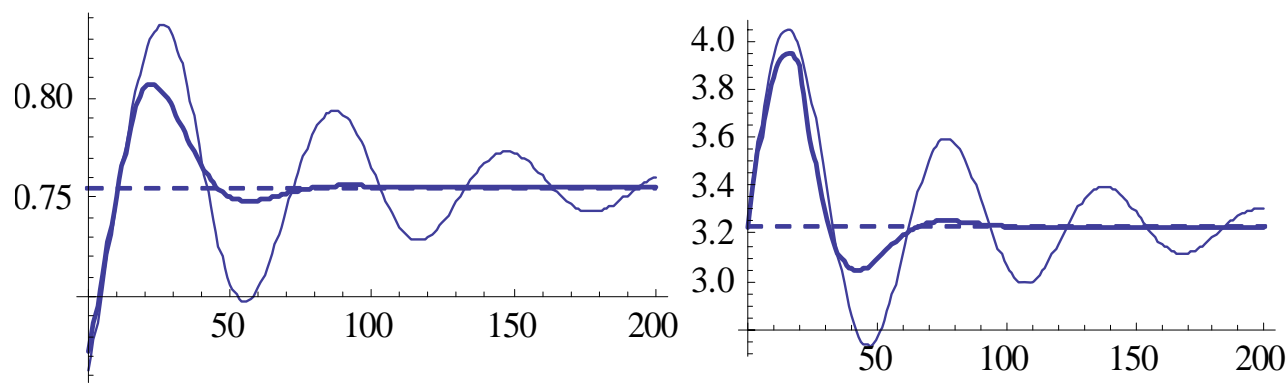

Figure 3: Paths of consumption (left-hand figure) and capital (right-hand figure) for learning under deficit financing (solid line) and under balanced budget (thin line) when government spending is endogenous. The horizontal dashed line shows the RE steady-state path.

Figure 3 illustrates that under learning Ricardian Equivalence fails for this fiscal regime even though Ricardian Equivalence holds under RE. ${ }^{17}$ The reason for failure of Ricardian Equivalence under learning stems from the assumed endogeneity of government spending with respect to the interest rate and the positive level of debt. Along the learning path the interest rate for $t \geq T$ deviates from its steady state value, leading to a change in government spending.

It is seen that for our numerical example the fluctuations of consumption and capital under learning are smaller with deficit financing than under balanced budgets. This result appears robust, though the magnitude of these differences is sensitive to the parameter values in the model. ${ }^{18}$ Intuitively, under both balanced budget and deficit financing, the initially high $r^{e}(t)$ reduces consumption, leading to an investment boom and to high levels of capital stock and low actual interest rates near period $T=20$. However, beginning in period $T=20$, under deficit-financing the resulting low actual

\footnotetext{
${ }^{17}$ In this example, for simplicity, the economy is assumed to be initially at the steady state with $r_{t}=\beta^{-1}$, so that under RE there is no change in government spending. Under the specified fiscal rule Ricardian Equivalence would fail under RE for non-steady state initial capital stocks, but a suitable modification of the tax and spending rules would preserve Ricardian Equivalence along a (non-steady-state) RE path.

${ }^{18}$ In other simulations, which are not shown, approximate Ricardian Equivalence is found to hold under learning when $\beta$ is close to one and $\delta$ close to zero. This last result is similar to what was found for a model without capital in Evans, Honkapohja, and Mitra (2009). On the other hand, smaller choices of the gain parameter $\gamma$ can lead to substantially larger differences between the balanced budget and deficit financing cases under learning.
} 
interest rates leads to higher $g_{t}$ under our fiscal rule, which crowds out investment. This endogenous fiscal mechanism reduces the magnitude of the fluctuations in capital and consumption; this is also reflected in less volatile fluctuations in wage and interest-rate expectations under deficit financing.

\subsection{Example when learning rule depends on debt}

So far we have considered learning rules for wages and interest rates that do not depend on current or past levels of debt or taxes. We now show that this is crucial for the Ricardian result to hold under learning.

Example 4: (expectations depend on debt) Suppose now that interest rate expectations depend on changes in the level of public debt, so that

$$
r^{e}(t)=r^{e}(t-1)+\gamma\left(r_{t}-r^{e}(t-1)\right)+\eta\left(b_{t}-b_{t-1}\right) .
$$

Government spending and taxation follow the fiscal rule of Example 1. In particular, the government spending sequence is exogenous.

We now consider the departures in the learning paths under balanced budget and deficit financing when agents use the learning rule (18). $\eta>0$ implies that agents believe the interest rate will go up when debt is increasing, while $\eta=0$ gives our baseline learning rule (16). The case of $\eta>0$ can be viewed as reflecting the belief that rising levels of public debt may lead to higher future real interest rates. Indeed, this is currently an issue of active discussion in policy circles, and thus this type of expectation formation may well be plausible, even if it is not fully rational.

Figure 4 illustrates the deviations between the paths under learning. The same parameter values are used as in Figure 1, i.e., $\sigma=1, \beta=0.99, \delta=$ $0.03, \alpha=1 / 3, \bar{g}=0.4, \bar{\tau}=0.3, T=20$, and $\gamma=1 / 20$. Initial conditions are set at $b_{0}=0, k_{0}=\bar{k}, r^{e}(-1)=\bar{r}$ and $w^{e}(-1)=\bar{w}$ i.e. we start at the steady state initially but let $\eta=0.002$. The thick horizontal line depicts the paths under RE and the learning path under balanced budget, while the solid curve shows the learning path under deficit financing when interest rate expectations depend on debt dynamics.

There are large differences in the two learning paths, which clearly illustrates the failure of Ricardian Equivalence when agents condition expectations on changes in debt levels in their learning rules. However, note that this learning rule allows the economy to converge to the steady state eventually 
since the level of debt stabilizes from period $T$ onwards for this financing rule.
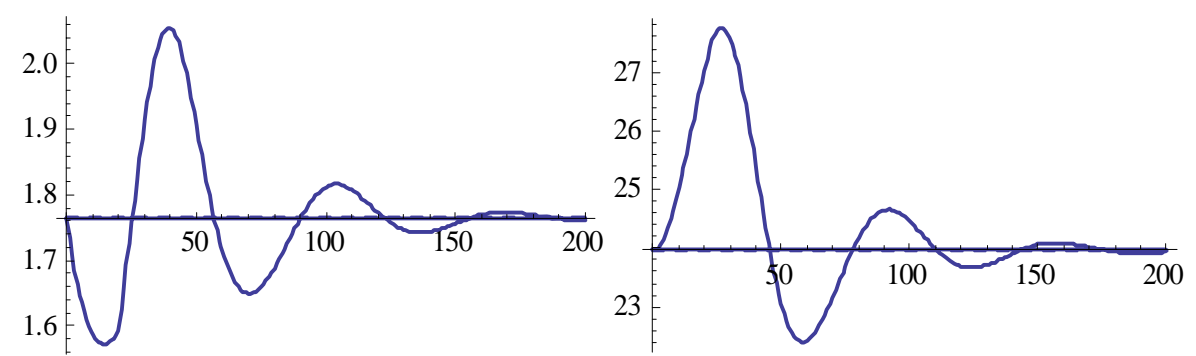

Figure 4: Paths of consumption (left-hand figure) and capital (right-hand figure) under learning for deficit financing (solid curve) and balanced budget (horizontal thick line) when the learning rule depends on debt.

\subsection{Discussion}

The results of this paper could be viewed in several ways. One possible reaction would emphasize that we have shown Ricardian Equivalence to be more general than previously recognized since we have shown that fully rational expectations are not required for its validity. Another possible reaction is that Ricardian Equivalence is unlikely to hold in practice because the assumptions we have provided for its validity are implausibly strong.

Our own view is that by reconsidering the issue without imposing perfect foresight or fully rational expectations a priori, we have made explicit several key hidden assumptions implicitly made when Ricardian Equivalence is examined under rational expectations. For example, under RE, if the standard assumptions are made that $g_{t}$ is an exogenous process and that the intertemporal budget constraint of the government is satisfied, then Assumption 4 is an implication of RE. By formulating the question under general expectations updating rules, we see that Assumptions 3 and 4 are logically separable, and that these assumptions are in principle separately testable. Quantitative studies of Ricardian Equivalence, such as Heathcote (2005), typically impose $\mathrm{RE}$ as a restriction, and the results of the current paper open up another possible channel for the failure of Ricardian Equivalence. As emphasized in our Assumption 4, the crucial issue is not whether expectations are fully 
rational, but whether or not expectations of future interest rates and wages depend on observed government financing variables.

In a similar vein, Assumption 2 makes explicit that for Ricardian equivalence to hold, agents need to incorporate the intertemporal budget constraint of the government into their forecasts. In their (local) analysis of monetary and fiscal policy interaction in a New Keynesian setting, Eusepi and Preston (2010b), who focus on the stability under least-squares learning of alternative policy regimes, treat the government's intertemporal budget constraint as an aspect of policymaker communication that facilitates stability. Our analysis and examples make clear that, under the assumptions stated, Ricardian Equivalence can hold even along transitional learning paths and with expectations that are not close to RE (and even for expectations that do not converge to RE asymptotically).

Finally, we emphasize that in stating the assumptions under which Ricardian Equivalence holds even when expectations are not rational, we are not claiming that Assumptions 1 through 4 are necessarily satisfied. This is an empirical matter. It is also possible that the assumptions are satisfied in certain countries and periods of time, even if they do not hold more generally.

\section{Conclusion}

In this paper, we have argued that validity of the Ricardian Equivalence proposition does not critically depend on the RE hypothesis. The Ricardian result can continue to hold if agents are dynamic optimizers given their subjective expectations and form their expectations using adaptive learning rules in place of RE. The central reason for our result is that agents are assumed to understand the government budget constraint and believe that the government transversality condition holds when evaluated at their subjective expectations. It is, however, crucial to assume that the learning rules are based on an appropriately restricted set of information variables.

Two new reasons for failure of the Ricardian result were found when expectations are formed using adaptive learning rules. One case is a fiscal regime in which government spending under deficit finance becomes endogenous solely as a result of dynamics that deviate from RE. A second reason for failure of Ricardian Equivalence under learning arises if, under deficit finance, agents condition their expectations on government's financial variables (taxes and debt). 
Our basic results for paths under learning were demonstrated under the usual assumptions required for Ricardian Equivalence under RE. Our analysis used the Ramsey model, which has been a standard framework for discussing the Ricardian proposition. To make our point in a compelling way, we have kept the analytical framework as simple as possible. We conjecture, however, that it will be possible to generalize our results in several directions.

One natural extension would be to stochastic Ramsey (or RBC) models that allow for exogenous stochastic shocks to productivity and government spending. Linearized models can be used to obtain the consumption function, and, with observable shocks included in the information set, our class of adaptive learning mechanisms would cover the least-squares learning rules standard in the adaptive learning literature. This extension would raise the possibility of further results in which Ricardian Equivalence may hold asymptotically in some cases in which our assumptions are violated. Other extensions include stochastic models with large shocks (in which linearization may be a poor approximation), the use of Bayesian learning instead of the anticipated utility framework, and the inclusion of distortionary taxes. ${ }^{19}$ Studying the implications of deficit financing versus balanced budget financing, when Ricardian Equivalence fails under learning, will also be of interest.

\footnotetext{
${ }^{19}$ Several of these topics are being examined in our current research.
} 


\section{Appendix: Derivations and Proofs}

\section{A Details for RE dynamics}

The steady state values of the various variables under RE for the Ramsey model are given by

$$
\begin{aligned}
\bar{k} & =\left(\frac{\beta^{-1}+\delta-1}{\alpha}\right)^{\frac{1}{\alpha-1}}, \\
\bar{y} & =\bar{k}^{\alpha} \\
\bar{c} & =\bar{k}^{\alpha}-\bar{g}-\delta \bar{k}, \\
\bar{r} & =1-\delta+\alpha \bar{k}^{\alpha-1}=\beta^{-1}, \\
\bar{w} & =(1-\alpha) \bar{k}^{\alpha} .
\end{aligned}
$$

The RE dynamics are obtained by taking a linear approximation around the steady state. For our purposes it is enough to analyze the balanced budget case $(\bar{\tau}=\bar{g})$ due to Ricardian Equivalence. Employing the same notation as in Ljungqvist and Sargent (2004), Section 11.7, we can write

$$
\phi_{0} k_{t+2}+\phi_{1} k_{t+1}+\phi_{2} k_{t}=A_{0}+A_{1} g_{t}+A_{2} g_{t+1} \text {. }
$$

The parameter values in our case take the form

$$
\begin{aligned}
\phi_{0}= & 1 \\
\phi_{1}= & -\left[\alpha(\bar{k})^{\alpha-1}+2-\delta-\right. \\
& \beta \sigma^{-1} \alpha(\alpha-1)(\bar{k})^{\alpha-2}\left[\bar{k}^{\alpha}+(1-\delta) \bar{k}-\bar{k}-\bar{g}\right] \\
\phi_{2}= & \beta^{-1} \\
A_{0}= & \left(1+\phi_{1}+\phi_{2}\right) \bar{k} \\
A_{1}= & 1, A_{2}=-1 .
\end{aligned}
$$

Since $g_{t}=\bar{g}$ for all $t$, it is easy to show that the linearized capital dynamics under $\mathrm{RE}$ reduce to

$$
k_{t+1}=\lambda_{2} k_{t}-\frac{1}{\lambda_{1}-1} A_{0}
$$

where $0<\lambda_{2}<1$ is the stable eigenvalue, and $\lambda_{1}$ the unstable eigenvalue, associated with the saddle-path RE solution to (19). Consumption is then determined as a residual from the market clearing equation (12). 


\section{B Examples with Learning and $g_{t}=\bar{g}$.}

In Examples 1 and 4 we have constant government spending, i.e. $g_{t}=\bar{g}$ for all $t$. Constant government spending also arises in Example 3 in the case of balanced budgets. The consumption function is given by (13). Agents are engaging in steady-state learning of interest rates and wages, given by (16) and (17), with initial expectations given by $r^{e}(-1)$ and $w^{e}(-1)$. Under this learning rule,

$$
D_{t, t+j}^{e}(t)=\prod_{i=1}^{j} r^{e}(t)=\left(r^{e}(t)\right)^{j} .
$$

The needed present values are

$$
\begin{aligned}
P V_{t}^{e}(g) & =\bar{g}+\bar{g} \sum_{j=1}^{\infty}\left(r^{e}(t)\right)^{-j}=\frac{\bar{g}}{1-r^{e}(t)^{-1}} \\
P V_{t}^{e}(w) & =w_{t}+\sum_{j=1}^{\infty}\left(D_{t, t+j}^{e}(t)\right)^{-1} w_{t+j}^{e}(t)=w_{t}+w^{e}(t) \sum_{j=1}^{\infty}\left(r^{e}(t)\right)^{-j} \\
& =w_{t}+w^{e}(t) \frac{1}{r^{e}(t)-1} .
\end{aligned}
$$

The consumption function (13) thus simplifies to

$$
c_{t}\left(1+S_{D}^{e}(t)\right)=r_{t} k_{t}+w_{t}+w^{e}(t) \frac{1}{r^{e}(t)-1}-\frac{\bar{g}}{1-r^{e}(t)^{-1}} .
$$

We also have the market clearing condition

$$
k_{t+1}=f\left(k_{t}\right)-c_{t}-\bar{g}+(1-\delta) k_{t} \text {. }
$$

This completes the description of the economy under learning and constant government spending (Examples 1 and 4), for both balanced budget and debt financing. These equations also hold for the balanced budget case of Example 3.

\section{Details for Deficit Financing in Example 3}

It is easily verified that $b_{0}=0$ and $b_{t+1}=b_{T}$ for all $t \geq T$. By Assumption $2(\mathrm{i})$, agents use the intertemporal budget constraint (15) of the government 
to compute $b_{T}^{e}(t)$ for all $0 \leq t \leq T-2($ with $t+J=T)$, i.e.,

$$
0=r_{t} b_{t}+(\bar{g}-\bar{\tau})+\sum_{j=1}^{T-t-1}\left(D_{t, t+j}^{e}(t)\right)^{-1}(\bar{g}-\bar{\tau})-\left(D_{t, T-1}^{e}(t)\right)^{-1} b_{T}^{e}(t) .
$$

Solving for $b_{T}^{e}(t)$ and using $D_{t, t+j}^{e}(t)=\left(r^{e}(t)\right)^{j}$ yields

$$
b_{T}^{e}(t)=\left(r^{e}(t)\right)^{T-t-1}\left[r_{t} b_{t}+(\bar{g}-\bar{\tau}) \frac{1-\left(r^{e}(t)\right)^{-(T-t)}}{1-r^{e}(t)^{-1}}\right] .
$$

For $0 \leq t \leq T-2$, we have

$$
\begin{aligned}
P V_{t}^{e}(g) & =g_{t}+\sum_{j=1}^{\infty}\left(D_{t, t+j}^{e}(t)\right)^{-1} g_{t+j}^{e}(t) \\
& =\bar{g}+\bar{g} \sum_{j=1}^{T-t-1}\left(r^{e}(t)\right)^{-j}+\left\{\bar{g}+\left(\beta^{-1}-r^{e}(t)\right) b_{T}^{e}(t)\right\}\left(\sum_{j=T-t}^{\infty}\left(r^{e}(t)\right)^{-j}\right) \\
& =\bar{g} \frac{1-\left(r^{e}(t)\right)^{-(T-t)}}{1-r^{e}(t)^{-1}}+\left\{\bar{g}+\left(\beta^{-1}-r^{e}(t)\right) b_{T}^{e}(t)\right\} \frac{\left(r^{e}(t)\right)^{-(T-t)}}{1-r^{e}(t)^{-1}} .
\end{aligned}
$$

where $b_{T}^{e}(t)$ is given by $(20)$.

For $t=T-1$, we have

$$
\begin{aligned}
P V_{t}^{e}(g) & =\bar{g}+\left\{\bar{g}+\left(\beta^{-1}-r^{e}(t)\right) b_{T}\right\} \sum_{j=1}^{\infty}\left(r^{e}(t)\right)^{-j} \\
& =\bar{g}+\left\{\bar{g}+\left(r^{e}(t)-r^{e}(t)\right) b_{T}\right\} \frac{\left(r^{e}(t)\right)^{-1}}{1-r^{e}(t)^{-1}}
\end{aligned}
$$

since $b_{T}^{e}(T-1)$ is known at $T-1$ i.e.

$$
b_{T}^{e}(T-1)=b_{T}=\bar{g}-\bar{\tau}+r_{T-1} b_{T-1} .
$$

Finally, for all $t \geq T$,

$$
\begin{aligned}
P V_{t}^{e}(g) & =\bar{g}+\left(\beta^{-1}-r_{t}\right) b_{T}+\left\{\bar{g}+\left(\beta^{-1}-r^{e}(t)\right) b_{T}\right\} \sum_{j=1}^{\infty}\left(r^{e}(t)\right)^{-j} \\
& =\bar{g}+\left(\beta^{-1}-r_{t}\right) b_{T}+\left\{\bar{g}+\left(\beta^{-1}-r^{e}(t)\right) b_{T}\right\} \frac{\left(r^{e}(t)\right)^{-1}}{1-r^{e}(t)^{-1}} .
\end{aligned}
$$




\section{References}

Arrow, K. J., and M. Intriligator (eds.) (1982): Handbook of Mathematical Economics, Volume II. North-Holland, Amsterdam.

BARro, R. J. (1974): "Are Government Bonds Net Wealth?, Journal of Political Economy, 82, 1095-1117.

(1989): "The Ricardian Approach to Budget Deficits," Journal of Economic Perspectives, 3, 37-54.

Bernheim, B. D. (1987): "Ricardian Equivalence: An Evaluation of Theory and Evidence," NBER Macroeconomics Annual, 2, 263-304.

Blanchard, O. J., and S. Fischer (1989): Lectures on Macroeconomics. MIT Press, Cambridge, Mass.

Bohn, H. (1992): "Endogenous Government Spending and Ricardian Equivalence," Economic Journal, 102, 588-597.

Bullard, J., and S. EusePi (2005): "Did the Great Inflation Occur Despite Policymaker Commitment to a Taylor Rule?," Review of Economic Dynamics, 8, 324-359.

Bullard, J., and K. Mitra (2002): "Learning About Monetary Policy Rules," Journal of Monetary Economics, 49, 1105-1129.

Cogley, T., and T. J. Sargent (2005): "The Conquest of US Inflation: Learning and Robustness to Model Uncertainty," Review of Economic Dynamics, 8, 528-563.

(2008): "Anticipated Utility and Rational Expectations as Approximations of Bayesian Decision Making," International Economic Review, 49, 185-221.

Eusepi, S., And B. Preston (2010a): "Expectations, Learning and Business Cycle Fluctuations," American Economic Review, forthcoming,.

(2010b): "Stabilizing Expectations under Monetary and Fiscal Policy Coordination," mimeo. 
Evans, G. W., and S. Honkapohja (1998): "Economic Dynamics with Learning: New Stability Results," Review of Economic Studies, 65, 23-44.

(2001): Learning and Expectations in Macroeconomics. Princeton University Press, Princeton, New Jersey.

(2003): "Expectations and the Stability Problem for Optimal Monetary Policies," Review of Economic Studies, 70, 807-824.

- (2009): "Learning and Macroeconomics," Annual Review of Economics, 1, 421-451.

Evans, G. W., S. Honkapohja, and K. Mitra (2009): "Anticipated Fiscal Policy and Learning," Journal of Monetary Economics, 56, 930953.

Feldstein, M. S. (1982): "Government Deficits, and Aggregate Demand," Journal of Monetary Economics, 9, 1-20.

Grandmont, J.-M. (1982): "Temporary general equilibrium Theory," in Arrow and Intriligator (1982), chap. 19, pp. 879-922.

(1998): "Expectations Formation and Stability of Large Socioeconomic Systems," Econometrica, 66, 741-781.

Heathcote, J. (2005): "Fiscal Policy with heterogeneous Agents and Incomplete Markets," Review of Economic Studies, 72, 161-188.

Hicks, J. R. (1946): Value and Capital, Second edition. Oxford University Press, Oxford UK.

Jacobs, D., E. Kalai, and M. Kamien (eds.) (1998): Frontiers of Research in Economic Theory. Cambridge University Press, Cambridge.

Kreps, D. M. (1998): "Anticipated Utility and Dynamic Choice," in Jacobs, Kalai, and Kamien (1998), pp. 242-274.

Ljungqvist, L., and T. J. Sargent (2004): Recursive Macroeconomic Theory, Second edition. MIT Press, Cambridge, MA.

Orphanides, A., and J. C. Williams (2005): "The Decline of Activist Stabilization Policy: Natural Rate Misperceptions, Learning and Expectations," Journal of Economic Dynamics and Control, 29, 1927-1950. 
(2007): "Robust Monetary Policy with Imperfect Knowledge," Journal of Monetary Economics, 54, 1406-1435.

Preston, B. (2005): "Learning about Monetary Policy Rules when LongHorizon Expectations Matter," International Journal of Central Banking, $1,81-126$.

Primiceri, G. E. (2006): "Why Inflation Rose and Fell: Policy-Makers' Beliefs and U. S. Postwar Stabilization Policy," Quarterly Journal of Economics, 121, 867-901.

Radner, R. (1982): "Equilibrium under Uncertainty," in Arrow and Intriligator (1982), chap. 20, pp. 923-1006.

Ricciuti, R. (2003): "Assessing Ricardian Equivalence," Journal of Economic Surveys, 17, 55-78.

Romer, D. (2001): Advanced Macroeconomics. McGraw-Hill, New York.

Sargent, T. J. (1993): Bounded Rationality in Macroeconomics. Oxford University Press, Oxford.

(1999): The Conquest of American Inflation. Princeton University Press, Princeton NJ.

- (2008): "Evolution and Intelligent Design," American Economic Review, 98, 5-37.

Sargent, T. J., N. Williams, and T. Zha (2006): "Shocks and Government Beliefs: The Rise and Fall of American Inflation," American Economic Review, 96, 1193-1224.

(2009): "The Conquest of South American Inflation," Journal of Political Economy, 117, 211-256.

SeAter, J. J. (1993): "Ricardian Equivalence," Journal of Economic Literature, 31, 142-190. 